\title{
A recessive form of congenital contractures and torticollis associated with malignant hyperthermia
}

\author{
U G FROSTER-ISKENIUS*, J R WATERSON†, AND JUDITH G HALL* \\ From ${ }^{*}$ the Department of Medical Genetics, Clinical Genetics Unit, University of British Columbi霖 \\ Vancouver, British Columbia, Canada; and the Department of Medical Genetics, Children's Hospik \\ Medical Center, Akron, Ohio, USA.
}

SUMmaRY Two families are presented, each with two affected sibs, all four of whom seem t⿱亠 have a newly described and specific form of congenital contractures (arthrogryposis). The affected subjects have congenital torticollis, dysmorphic, asymmetrical, myopathic facia features, and progressive scoliosis. Two sibs had cleft palate. Malignant hyperthermia has occurred in two of the patients.

The conditions which present with congenital contractures are a very heterogeneous group of disorders. They include those with a known neurological or myopathic basis, as well as many idiopathic forms of unknown aetiology. We report two pairs of sibs from two unrelated families who seem to have a specific genetic form of congenital contractures (arthrogryposis). The affected subjects have congenital torticollis and characteristic dysmorphic craniofacial features, including facial asymmetry, asymmetrical, myopathic facial movements, ptosis, and cleft palate (in two sibs). They also have progressive scoliosis. Intelligence is high normal. Two of the patients have had episodes of malignant hyperthermia.

\section{Case reports}

FAMILY 1

Patient 1 was the first child of healthy, nonconsanguineous parents. Maternal age at birth was 22 years and paternal age 28 years. Family history was unremarkable. One elective termination had occurred before this conception. Pregnancy was complicated by spotting at three months and polyhydramnios late in pregnancy. Decreased fetal movement was noted at 34 weeks of pregnancy. The patient was delivered at 39 weeks by caesarean section because of failure of progression of labour. His birth weight was $3650 \mathrm{~g}$ (50th centile), length 50 cm (50th centile), OFC $36.6 \mathrm{~cm}$ (50th centile Apgar score was 2 at one minute and 5 at five minutes and he required vigorous resuscitation an therapy for respiratory distress.

At birth (fig 1) he was profoundly hypotonic and had multiple congenital contractures and facie日 anomalies. He had bilateral equinovarus deformities of the feet. The wrists were fixed in hyperextensiog and the fingers were overlapping, with lack of movement in the IP and MP joints. No finger of palm creases were present. Muscle tone was hypo: tonic and his muscle mass appeared decreased. He had a scaphocephalic skull. A Pierre-Robin anoma? with micrognathia and a $\mathrm{V}$ shaped cleft palate were present. Two natal teeth were present. He had a flat midface and his left palpebral fissure was downwarg slanted. Torticollis was present on the left. $\mathrm{De}_{-}^{-}$ creased facial expression and generalised facia weakness were present. He had webbing of the neck. His chest was broad and asymmetrical, wit the right side more prominent than the left, and th sternum was mildly depressed. Chest $x$ ray showed very thin ribs. At the age of two years, three montlis he was on the 10th centile for height $(85.4 \mathrm{~cm} \%$ below the 5th centile for weight $(8.9 \mathrm{~kg})$, with $a$ a OFC on the 50 th centile $(47.5 \mathrm{~cm})$. Physical finding at that age included a persistent torticollis on the lef and plagiocephaly with a prominent metopic suture which had fused prematurely. He had rather fuif cheeks, a downturned, small mouth, and a tendenç to hold it open with some drooling. The facio muscles appeared hypotonic and there was little movement of the face. His face was asymmetric 


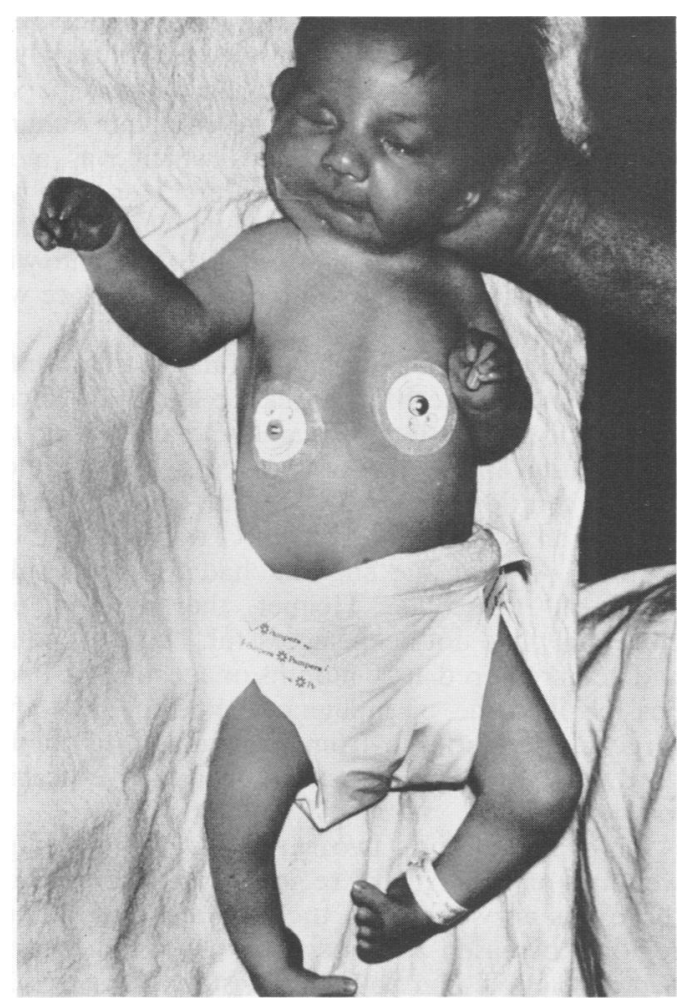

FIG 1 Patient 1 shortly after birth. Note asymmetrical face, torticollis, excessive skin, and webbing of neck.

with flattening of the left side and a more prominent right side. He had a small nose. There were downward slanting palpebral fissures and ptosis of the eyelids, both being more obvious in the right eye than in the left. Facial movements showed asymmetry in that the right side of the face moved less than the left. Both hands showed ulnar deviation and camptodactyly in the IP joints of the second, third, fourth, and fifth fingers. Partial proximal cutaneous syndactyly of the second and third fingers was also noted. The thumbs were dislocated and fixed in the IP joints. There was a limited range of movement in his legs with the knees lacking $10^{\circ}$ of extension and the ankles lacking full dorsiflexion and full plantar flexion. A mild conductive hearing loss was found bilaterally. Motor milestones were within normal limits. His speech development was delayed because of his cleft palate. He had learned to sit at the age of five and a half months and started to speak a few words at the age of two years, three months. His vocabulary at this age was about two months behind.

At the age of four years, 10 months (fig 2 ) he was

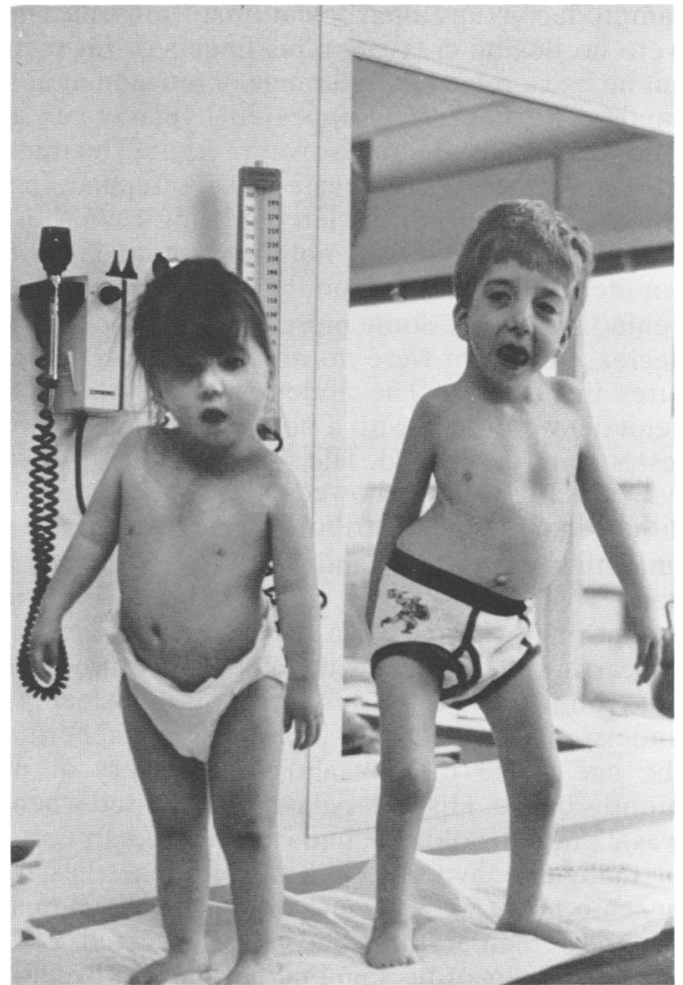

FIG 2 Patients 2 and 1 showing similar features, with facial asymmetry, myopathic facies, mild ptosis, persistent torticollis, scoliosis, and webbing across joints.

below the 5th centile for height and weight $(89 \mathrm{~cm}$, $13.5 \mathrm{~kg}$ ). His OFC was on the 50 th centile for his age $(51 \mathrm{~cm})$. Craniofacial features showed the same anomalies as described at the age of two years, three months. Palpebral fissure length $(2.5 \mathrm{~cm})$ and inner canthal distance $(2.7 \mathrm{~cm})$ were appropriate (50th centile) to his head circumference. He had a long philtrum $(2.0 \mathrm{~cm})(\geq 2 \mathrm{SD})$, micrognathia, and a repaired cleft palate. His voice was very nasal. The teeth were carious. The ears were mildly posteriorly rotated, but of normal size $(5.4 \mathrm{~cm})(50$ th centile) and normal shape. His chest circumference measured $54 \mathrm{~cm}$ (50th centile) with an internipple distance of $16 \mathrm{~cm}$ ( $\geq 97$ th centile). The chest was clear. No abnormal heart murmurs were heard. A marked thoracolumbar scoliosis with a $55^{\circ}$ curve was present with $17^{\circ}$ of kyphosis. The kyphoscoliosis was apparently due to a muscular imblance, since no vertebral defects were found on $x$ ray. Webbing of his neck and in the axillary region was present. There were dimples at both elbows. The upper limbs showed a good passive range of movement. His hands were $11 \mathrm{~cm}$ long (10th centile), with slight 
camptodactyly and ulnar deviation still present. There were no flexion creases on his fingers or his palms, but he had a relatively full range of movement in the hands. The fingernails appeared hyperconvex and mild tapering of the fingers was present. The muscle mass in his arms was decreased. A discrepancy in leg length was seen with the left leg being $1 \mathrm{~cm}$ shorter than the right. He did not have pterygia in the popliteal or inguinal region, but had some extra skin behind his knees. Some muscle mass in the legs was decreased. There were no obvious flexion contractures in his hips. The abdomen was normal. His genitalia were male with a normal size penis and his testes were descended. His skin was soft.

Dermatoglyphics showed no distal triradii on either hand. The distribution of pattern on the fingertips was: right hand $L^{u}, W, L^{u}, L^{u}, A$; left hand $\mathrm{W}, \mathrm{W}, \mathrm{L}^{\mathrm{u}}, \mathrm{L}^{\mathrm{u}}, \mathrm{L}^{\mathrm{u}}$. Intellectual development was normal with an IQ in the high normal range.

Scarring of the sclera developed because he did not completely close his eyes during sleep. He underwent operations for bilateral inguinal hernia at the age of 13 months and foot surgery at nine months of age. His cleft palate was repaired when he was 22 months old. He had experienced an episode of malignant hyperthermia during anaesthesia for his club foot repair at nine months. Serious raising of body temperature had also occurred during surgical repair of his inguinal herniae. Between the age of three and four years a progressive scoliosis developed which was treated with a brace and with physiotherapy. Laboratory investigations showed a normal to low CK of 24 units. A muscle biopsy of the left abductor hallucis longus showed mild neuropathic changes. Electron microscopy studies were performed but did not show specific changes for a congenital myopathy.

Patient 2 is the younger sister of patient 1 . She was born after an uneventful pregnancy, monitored with realtime ultrasound for contractures and fetal movements at 16,20 , and 24 weeks of gestation. Abnormal fetal movements were not recognised during the prenatal ultrasound investigations. She was born by repeat caesarean section one week after term. Her birth weight was $3300 \mathrm{~g}$ (50th centile). At birth she was noted to have torticollis on the right side and contractures of the limbs similar to those seen in her brother, including a metatarsus adductus on the left side and slight ulnar deviation of the fingers with camptodactyly of the third, fourth, and fifth fingers bilaterally. She had long, tapering fingers and overlapping toes (third over second).

At the age of six months her height was on the 10th centile $(62.5 \mathrm{~cm})$, her weight on the 25 th centile, and her OFC on the 50 th centile $(42 \mathrm{~cm})$. Her skull was plagiocephalic and her face asymmet- rical, with the left cheek showing more fullness than the right. She had a prominent metopic suture which? had fused prematurely. The torticollis was persistent. Her craniofacial features were further remark $-\frac{\bar{c}}{\bar{c}}$. able for a ptosis of her eyelids which was more obvious on the right than on the left. Her nose was slightly deviated. Her mouth was downturned andes small, with a tendency to be held open and with $\overrightarrow{0}$ intermittent drooling. A V shaped cleft palate wasalso present.

She could not open her mouth fully. At 11 months? she was still on the 10th centile for length $(69.5 \mathrm{~cm}$ and on the 5th centile for weight with an OFC on thei 25 th centile. By the age of two years she was below the 5 th centile for length $(80.4 \mathrm{~cm})$ and on the 5 thcentile for weight $(9.9 \mathrm{~kg})$. OFC was $48 \mathrm{~cm}(50 \mathrm{th}+$ centile). At that age she still had the right sided persistent torticollis. Helmet therapy for plagiocephaly had not been successful. Her cleft palate had been repaired at 20 months of age and she had possible episode of malignant hyperthermia after surgery. She suffered from recurrent otitis media? At the age of 19 months a mild conductive hearing $\overrightarrow{0}$ loss was noted.

On examination at two years of age (fig 2) slight webbing of her axillary regions was observed, bue there was no webbing in the popliteal and inguinas region. Increased asymmetry of her facial features had developed. Her palpebral fissures measured 2. 30 $\mathrm{cm}$, and her inner canthal distance $2.4 \mathrm{~cm}(25 \mathrm{th} P$ centile). She had a long philtrum $(1.6 \mathrm{~cm})(\geq 2 \mathrm{SD}) \overrightarrow{\overrightarrow{0}}$ Her primary teeth appeared mottled. Her chest was clear without abnormal heart sounds. Chest cir? cumference was $51 \mathrm{~cm}$, on the 75th centile for her. chronological age, and her internipple distance waš $12.5 \mathrm{~cm}$ (95th centile). A mildly depresses sternum was present. A mild scoliosis had developed. Her hands showed both index fingerş curved ulnarly with stiffness in the IP joints. HeP affected left leg showed a full range of movement in the knee. Her motor and intellectual developmens was unremarkable. She had appropriate speechp development for her age. Her voice had a high nasa?. quality. Her IQ, however, appeared high normal. ơ

FAMILY 2

Patient 3 was the second child born to a healthy 28 year old mother and an unrelated, healthy 30 yearo old father. The family already had a healthy历 daughter. The pregnancy itself was basically uncom + ? plicated. The mother took vitamins throughout and a cough medicine containing caramiphen edisylate chlorpheniramine maleate, phenylpropanolamine hydrochloride, isopropamide iodide, and alcoho $\mathbb{R}$ during the first trimester. There was spotting for 
few days during the fifth month. Fetal movement was considered normal.

The patient was born at 36 weeks of gestation. Membranes ruptured and labour was subsequently induced. Delivery was spontaneous vertex. Apgar scores were 6 at one minute and 7 at five minutes. His birth weight was $2310 \mathrm{~g}$ ( 25 th centile) (fig 3). At birth, multiple joint contractures and facial abnormalities were noted. His hips were held in partial flexion and abducted. His knees were extended. $\mathrm{He}$ had bilateral equinovarus feet with both forefeet in the varus position. In the upper limbs there were fixed flexion contractures of $90^{\circ}$ at the elbow and the wrists were completely flexed. He had long tapering fingers with long nails and palmar creases were abnormal but not further specified at birth. Craniofacial features included an OFC on the 50th centile $(32.4 \mathrm{~cm})$ and a brachycephalic skull with a downward sloping forehead. The nose was deviated to the right with a prominent nasal bridge and flat nasal tip. The eyes appeared widely set; the inner canthal distance measured $2.0 \mathrm{~cm}(1 \mathrm{SD})$ and the outer canthal distance was $6.25 \mathrm{~cm}$ ( $\geq 2$ SD). Palpebral fissure length was 2.0 for the right and 1.9 for the left eye ( $\geq 2$ SD). The eyes showed mild proptosis. The mouth had a prominent cupid bow. The philtrum was rather long $(1 \cdot 1 \mathrm{~cm}, 2 \mathrm{SD})$. His mandible was small. He had anteverted, rounded shoulders and his neck showed a palpable mass which was diagnosed as a cystic hygroma. His chest was symmetrical with a circumference of $30.25 \mathrm{~cm}$ (mean) with widely spaced nipples. Internipple distance was $9 \mathrm{~cm}(2 \mathrm{SD})$. His genitalia were male with a small, normal appearing penis, but undescended testes and a poorly developed scrotal sac. The skin showed a pigmented intradermal naevus on the left posterolateral side of the thorax. The boy died four days after birth from respiratory insufficiency. Additional findings at necropsy were only two vessels in the umbilical cord and pleuricystic renal disease with a moderate number of ectatic tubules and ectatic Bowman's capsule. The musculature, especially of the lower extremities, was pale whitish in colour. Scanty muscle tissue was replaced by fibrous and adipose tissue. Sections of the muscle showed atrophy of individual scattered fibres and of entire fascicles with marked endomysial and perimysial fibrosis. Neuropathological investigations showed diffuse and focal bilateral but asymmetrical absence of motor neurones at all levels of the spinal cord, most severe in the cervical region. Torticollis, asymmetrical face, and ptosis of the eyelids were not described at birth, but appear to have been present, as seen in the patient's photographs (fig 3).

Two first trimester spontaneous abortions occurred between patient 3 and patient 4 . Both of those pregnancies were also complicated by vaginal infections treated with metronidazole (Flagyl).

Patient 4 is the younger brother of patient 3 . Maternal age was 32 years and paternal age 33 years when he was born. Pregnancy history was uneventful. There was use of metronidazole in the fourth month of pregnancy. Fetal movements were felt to be normal. Ultrasound monitoring was performed at

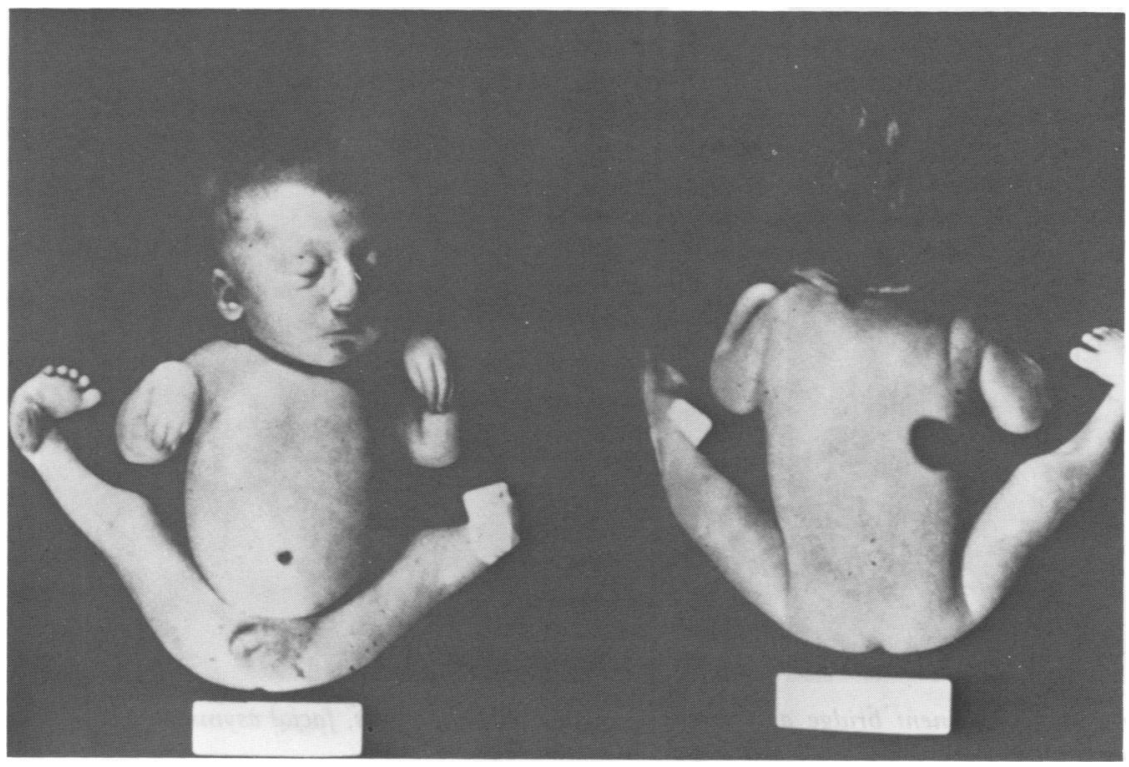

FIG 3 Patient 3 . Post mortem photographs. Note fixed contractures and prominent bridge of nose. 
two months, five months, and just before delivery. No comment on fetal movement was made. He was delivered at term by caesarean section because of breech presentation. His birth weight was $2810 \mathrm{~g}$ ( 25 th centile). He was found to have flexion contractures of his joints at birth, including a torticollis to the left side. Physical examination at the age of 13 months (fig 4) showed that he was on the 25 th centile for length $(25 \mathrm{~cm})$ and on the 50th centile for weight $(8 \cdot 2 \mathrm{~kg})$. His head circumference measured $43.5 \mathrm{~cm}$ (50th centile) while his head shape was brachycephalic and plagiocephalic. The anterior fontanelle was closed. He had a long face with torticollis on the left side. Other craniofacial features included an inner canthal distance of $2.0 \mathrm{~cm}$ (3rd centile) and an outer canthal distance of $5.7 \mathrm{~cm}$ ( 3 rd centile). His ears were asymmetrical and the right ear had a poorly formed helix. Ear length was $4.8 \mathrm{~cm}$ (25th centile). The ears appeared low set and slightly posteriorly rotated. His nose had a flat tip and a prominent nasal bridge. He had micrognathia and a broad alveolar ridge which gave the impression of a high arched palate. His teeth appeared small. Decreased and asymmetrical facial movements were noted.

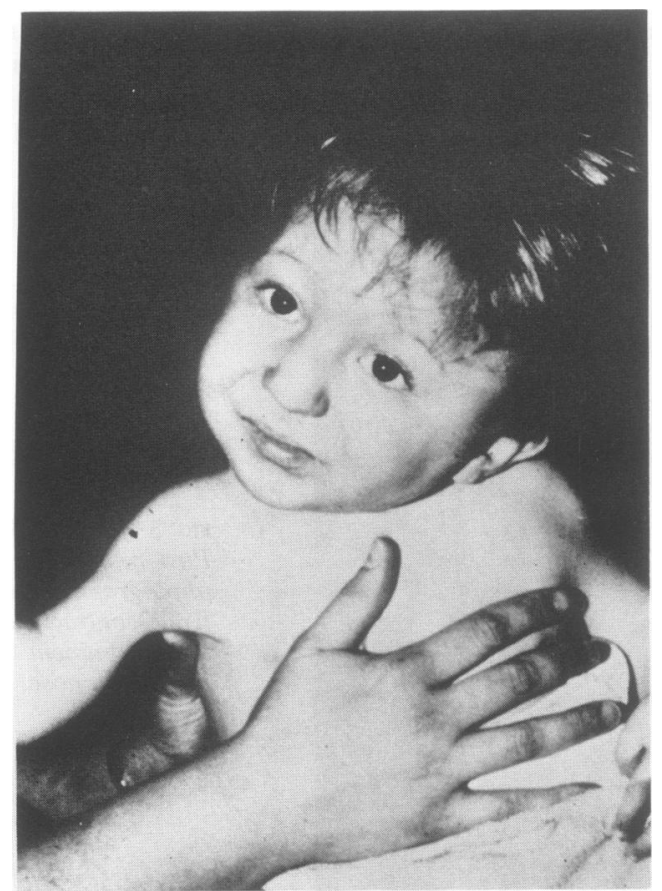

FIG 4 Patient 4. Note torticollis, prominent bridge and depressed tip of nose, facial asymmetry, and abnormal ear.
The neck was short with mild webbing mainly on $\overrightarrow{\vec{F}}$ the left side. The range of motion of his head was $\stackrel{?}{\rightarrow}$ limited. His chest was symmetrical with a mild pectus excavatum and increased AP diameter. No $\frac{\bar{\sigma}}{\bar{\rho}}$ abnormal heart murmurs were noted. His shoulders $\frac{{ }_{0}}{\vec{\phi}}$ were anteriorly rotated. Decreased range of move- $\propto$ ment was observed in all joints. The upper limbs के showed dimples over the elbows and wrists. Campto- $\vec{\circ}$ dactyly of the fingers was present with webbing between the metacarpophalangeal and proximal $\vec{\omega}$ phalangeal joints. Palmar creases showed bilateral simian creases with a decreased number of plantar and palmar creases. His feet were still in bilateral is talipes equinovarus position. His genitalia were $\stackrel{\sim}{i}$ male with undescended testes and a poorly de- $\vec{P}$ veloped scrotum with a prominent median raphe.

He learned to sit independently at nine months $ᄋ$ and started to talk at 18 months. At the age of 18 months he had an episode of unconsciousness 7 which seemed to be related to an apnoeic spell. He $\underset{0}{D}$ recovered from this episode with no apparent sequellae. When examined at the age of 19 months he was below the 5 th centile for length $(75 \mathrm{~cm})$ and $\vec{\bullet}$ weight $(8.4 \mathrm{~kg})$. His head circumference measured $\infty_{\infty}^{\infty}$ $45.5 \mathrm{~cm}(<5$ th centile). He had downward slanting

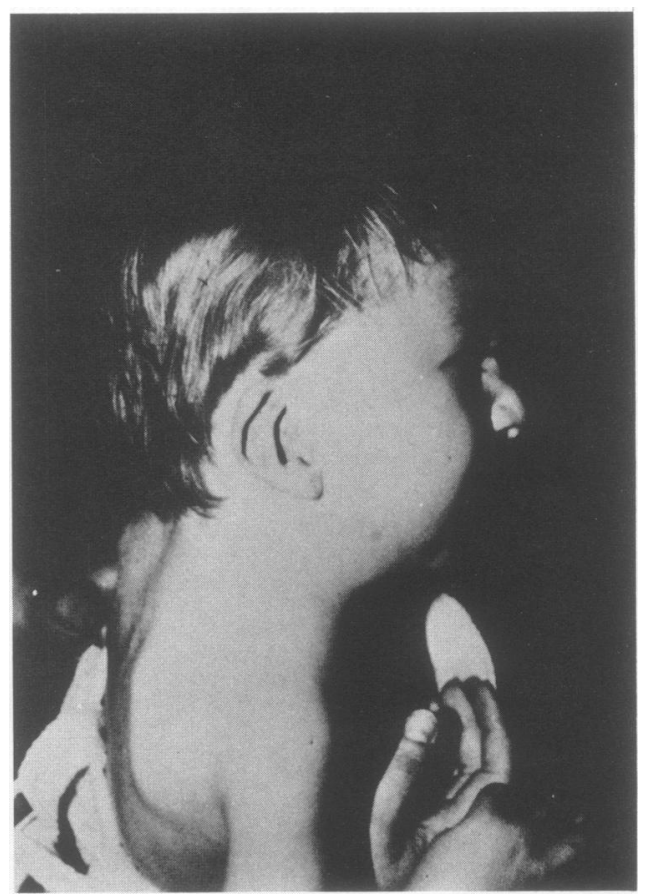

FIG 5 Patient 4. Note ptosis, facial asymmetry, and persistent contractures. 
palpebral fissures and some ptosis of the eyelids. His fine motor and intellectual development were normal to high normal. He still requires assistance in walking at two and a half years. He has developed mild scoliosis. The torticollis has responded relatively well to bracing therapy. A muscle biopsy at the age of two years showed atrophic muscle cells, only type I muscle fibres, and an overall impression of degenerated skeletal muscle with enlargement and remodelling of motor units consistent with a neuropathy. Laboratory investigations revealed a low serum CK level of 29 units (normal for age 35 to 232 units).

\section{Summary of clinical findings (table 1)}

These four patients had several features in common. The most striking were torticollis, asymmetry of the face, and decreased facial movements. On the side of the torticollis, the side of the face was flattened with a prominent cheek on the opposite side. The facial features were also remarkable because of ptosis of the eyelids and downturned corners of the mouth. They had myopathic facial expressions. The philtrum, when measured, was long ( $\geq 2$ SD). Two sibs had cleft palate and one had prominent alveolar ridges which gave him a high appearing palate.
Micrognathia and low set, posteriorly rotated ears were also noted in all patients. In one patient, the additional finding of two natal teeth was observed. Congenital flexion contractures were found in all of them and included ulnar deviation of the fingers in the IP and MP joints, fixed wrists and elbows with overlying dimples, equinovarus position of the feet, and contractures (both flexion and extension) of the knee joints. Webbing of the neck and progressive axillary webbing were also present in all living patients. Scoliosis developed between the ages of two and three years in the living patients and has been progressive in nature. No vertebral defects were found. Episodes of malignant hyperthermia occurred in both patients from family 1 under general anaesthesia. The other two patients either did not have surgery or exposure to anaesthesia or preventive precautions have been taken. Intellectual and motor development appeared to be normal in the living patients. Two patients had developed conductive hearing loss, possibly related to chronic otitis, and one patient had an episode of apnoea. Muscle biopsies were performed in two patients and revealed no specific myopathic changes, but mild neuropathic changes. Neuropathological examination at necropsy in one patient showed atrophy of muscle fibres consistent with anterior horn cell loss.

TABLE 1 Summary of clinical findings.

\begin{tabular}{|c|c|c|c|c|}
\hline & Patient 1 & Patient 2 & Patient 3 & Patient 4 \\
\hline Sex & $\mathbf{M}$ & $\mathrm{F}$ & $\mathbf{M}$ & $\mathbf{M}$ \\
\hline Age at last examination & $4 y$ & $2 y$ & 36 wk gest & $19 \mathrm{mth}$ \\
\hline Plagiocephaly & + & + & + & + \\
\hline Ptosis & + & + & & $(+)$ \\
\hline Facial asymmetry & + & + & & + \\
\hline Torticollis & + & + & + & + \\
\hline Long philtrum & + & + & + & + \\
\hline Scoliosis & + & + & & + \\
\hline Birth (wk) & 41 & 41 & 36 & Term \\
\hline Birth weight $(\mathrm{g})$ & $3650(50 \%)$ & $33(x)(50 \%)$ & $2310(25 \%)$ & $2800(25 \%)$ \\
\hline$<5 \%$ length & + & + & - & + \\
\hline Pectus excavatum & + & - & - & + \\
\hline IQ & $\mathrm{n}$ & $\mathbf{n}$ & & $\mathrm{n}$ \\
\hline Decreased muscle mass & + & + & + & + \\
\hline Anterior horn cell loss & $?$ & $?$ & + & $?$ \\
\hline Malignant hyperthermia & + & + & - & - \\
\hline Long, tapering fingers & + & + & + & + \\
\hline Flexion contractures (elbows) & - & - & + & + \\
\hline (wrists) & & & + & + \\
\hline (knees) & + & + & Extended & + \\
\hline (ankles) & + & + & + & - \\
\hline (hips) & + & + & + & + \\
\hline Camptodactyly & + & + & + & + \\
\hline Pes equinovarus & + & + & + & + \\
\hline Neck webbing & + & + & + & + \\
\hline Axillary webbing & + & + & - & + \\
\hline Cleft palate & + & + & - & - \\
\hline Deviated nose & - & + & + & - \\
\hline Small mandible & + & + & + & + \\
\hline Hearing loss & + & + & - & \\
\hline Low set ears, posteriorly rotated & + & + & & + \\
\hline
\end{tabular}




\section{Discussion}

In the two sibships reported here congenital contractures are associated with a unique pattern of anomalies, the most striking of which are torticollis and malignant hyperthermia.

Torticollis is a fixed contraction of the neck muscles, usually occurring at or around the time of birth. It primarily involves the sternocleidomastoid muscle or those muscles supplied by the spinal accessory nerve. The persistent muscle contraction in the neck leads to rotation of the head to one side such that the chin points to the opposite side from the contracted muscle. The frequency of congenital torticollis is estimated at between $4 / 1000$ to $1 / 150000 .{ }^{1}$ Different aetiological factors have been considered, including birth injuries, abnormal intrauterine position, infectious vascular disturbances, and neurogenic causes. ${ }^{2}$ It is not entirely clear whether torticollis usually begins before birth or occurs because of the birth process. Familial occurrence of congenital torticollis has been reported, but appears to be rare. ${ }^{3}$ Associated anomalies are common with torticollis. The most frequent is hip dysplasia, occurring in 14.8 to $20 \%$ of cases of torticollis. ${ }^{4}$ Other problems frequently mentioned include club foot, pyloric stenosis, seizures, and mental retardation. Cleft palate and natal teeth have been reported in one patient with congenital torticollis without further detailed description of the physical findings. ${ }^{5}$ Among the associated anomalies frequently observed and thought to be secondary to the torticollis are asymmetry of the face and skull, including flattening of the frontal prominence of the affected side of the head, epicanthic folds, and short eyebrows. Plagiocephaly and facial asymmetry are seen in 15 to $100 \%$ of patients with torticollis and may be caused by late intrauterine moulding of the head $^{6}$ or as a consequence of pressure after birth. In the four patients described here, the plagiocephaly, flattening, and asymmetry of the face may well be the consequence of what can be called the 'torticollis sequence', that is, they are secondary to the persistent contracture of the neck muscles that are part of the torticollis condition itself.

In the two sibships reported here congenital torticollis was associated with other facial anomalies, congenital contractures of the limbs, webbing of the neck and axillary region, and, in two patients, with episodes of malignant hyperthermia. The facial anomalies in these patients include ptosis of the eyelids, downward slanting palpebral fissures, downturned corners of the mouth, long philtrum, micrognathia, cleft palate, prominent alveolar ridges, natal teeth, and an overall myopathic facial expression. All of these facial anomalies cannot satisfactorily be explained as a consequence of the $\overrightarrow{\vec{D}}$ torticollis but rather appear to be part of the specific $\vec{\sigma}$ condition we are reporting. Muscle weakness of $\frac{}{}$ prenatal onset could explain many of the facial $\frac{\bar{c}}{\overline{0}}$ findings in these children and could possibly have $\vec{\nabla}$ predisposed to torticollis developing before or at birth.

The congenital contractures in our patients in- $\overrightarrow{0}$ clude ulnar deviation of the fingers at the IP and MP joints, contractures of the wrists and elbows with overlying dimples, contractures of the feet and ankles (primarily equinovarus position of the feet), and contractures of the hips and knees. Later in life webbing of the neck, but also in the axillary and the iv inguinal regions, as well as progressive scoliosis, $\vec{\circ}$ have developed in the three living patients. While scoliosis with webbing of cervical vertebrae has been 을 described in patients with torticollis, ${ }^{7} x$ rays of the spine in our patients did not reveal vertebral anomalies.

Among conditions with congenital contractures and pterygia, at least five separate groups have been described. ${ }^{8}$ Progressive scoliosis together with con- $\vec{\emptyset}$ genital contractures and pterygia across joints in the neck region are found in some patients with the autosomal recessive multiple pterygium syndrome. Patients with the multiple pterygium syndrome show progressive axillary and neck webbing and progression of the contractures, as well as myopathic facial expression, ptosis of the eyelids, and overall muscular wasting. Normal intelligence and lack of specific myopathic changes in muscle biopsy are additional similarities of the condition described here with the multiple pterygium syndrome. However, in patients with the multiple pterygium syndrome, webbing involves most major joints, including the elbows and popliteal and inguinal region, while in our two sibships webbing has been limited to the neck, axillary, and inguinal regions. Furthermore, the contractures in our patients appear to be less severe and more responsive to physical therapy and bracing therapy than usually seen in multiple pterygium syndrome. However, all our patients are young, less than five years old, and pterygia formation may $N$ increase with age and progression of muscle wasting. $N$ Nevertheless the presence of torticollis and malig- $N$ nant hyperthermia without vertebral anomalies sug- $\omega$ gests that our patients represent a distinct entity.

Malignant hyperthermia was mentioned in $a \stackrel{0}{=}$ patient with congenital contractures, ${ }^{9}$ but has not $\mathbb{D}_{\overparen{D}}$ been a reported feature of the multiple pterygium ? syndrome. Episodes of malignant hyperthermia occurred with anaesthesia in the two sibs of family 1 . The other living patient had not been exposed to $\frac{?}{\mathbb{D}}$ anaesthesia, as preventive precautions were taken $\propto$ beforehand. Malignant hyperthermia, which is 
characterised by a marked rise in body temperature, rigidity of muscle, cardiac arrhythmia, and further metabolic abnormalities, is often triggered by inhalational and muscle relaxing drugs but also by some anaesthetics. Occasionally it can also be a response to physical or emotional stress. Perhaps birth represented such a stress to patient 3 , although no rise in body temperature was reported before or at birth.

Incidence figures for malignant hyperthermia range between 1 in 10000 to 1 in 100000 in response to general anaesthesia. ${ }^{10}$ Malignant hyperthermia can occur as an isolated autosomal dominant trait but it has also been observed in several different muscle diseases such as muscular dystrophy and central core disease. "12 ${ }^{12}$ Non-specific myopathic abnormalities in muscle biopsies from patients with malignant hyperthermia or at risk for it are commonly found. ${ }^{13} \mathrm{CK}$ is otten raised in asymptomatic subjects, so it is of interest that two of our patients actually have low CK levels.

A well documented condition of malignant hyperthermia and a progressive myopathy has been reported as King's syndrome. ${ }^{14}$ This disorder presents with short stature, kyphoscoliosis, pectus carinatum, hypoplastic mandible, ptosis, epicanthic folds, undescended testes in the male, and a slowly progressive myopathy. Both male and female patients have been described. ${ }^{15}{ }^{16}$ Raised CK levels in other family members and a mild myopathy in two previous generations in one family suggest a dominant mode of inheritance with possible reduced penetrance in King's syndrome. ${ }^{16}$ Several features distinguish the condition described here from King's syndrome; the most prominent are the congenital contractures, congenital torticollis, and progressive development of webbing.

The findings in our patients are different from features seen in King's syndrome and the multiple pterygium syndrome (table 2 ). We suspect that we are observing a new and distinct condition; the pathogenesis, however, is not yet clear. Since persons of both sexes are affected in family 1 , and the parents do not show features of the disorder, an autosomal recessive mode of transmission is certainly possible, even though there is no consanguinity in either family. In both families no unaffected child has been born after the affected children and both of the first affected children followed either a termination of pregnancy or a spontaneous abortion. This makes an environmental factor aetiologically possible; however, no common drug, infection, or prenatal exposure to any common agent could be identified.

The clinical findings of prenatal onset of contractures, progressive muscular wasting, myopathic
TABLE 2 Comparison of features with King's syndrome and multiple pterygium syndrome

\begin{tabular}{|c|c|c|c|}
\hline . & $\begin{array}{l}\text { King's } \\
\text { syndrome }\end{array}$ & $\begin{array}{l}\text { Multiple } \\
\text { pterygium } \\
\text { syndrome }\end{array}$ & Patients $I \rightarrow 4$ \\
\hline Ptosis & + & + & + \\
\hline Lordosis & + & + & + \\
\hline Nasal speech & + & + & $+(3 / 4)$ \\
\hline Otitis media & + & $?$ & $+(2 / 4)$ \\
\hline $\begin{array}{l}\text { Downward slanting } \\
\text { palpebral fissures }\end{array}$ & $(+)$ & + & $+(1 / 4)$ \\
\hline Micrognathia & + & + & + \\
\hline Kyphoscoliosis & + & $\begin{array}{c}+ \text { with vertebral } \\
\text { abnormalities }\end{array}$ & + \\
\hline Short stature & + & + & + \\
\hline Asymmetrical face & $+\underset{\text { from }}{\text { picture }}$ & - & + \\
\hline Midface hypoplasia & + & - & + \\
\hline Raised CK & + & $(+)$ & - \\
\hline Malignant hyperthermia & + & $(+)$ & $+(2 / 4)$ \\
\hline $\begin{array}{l}\text { Motor development } \\
\text { slightly retarded }\end{array}$ & + & $(+)$ & $+(3 / 4)$ \\
\hline Webbing across joints & - & + & + \\
\hline Contractures & - & + & + \\
\hline Torticollis & $?$ & - & + \\
\hline Low set cars & + & - & + \\
\hline Pectus carinatus & + & + & $+(2 / 4)$ \\
\hline Cryptorchidism & + & + & $+(2 / 3)$ \\
\hline Muscular weakness & + & + & + \\
\hline Renal anomalies & - & - & $+(1 / 4)$ \\
\hline Multiplc cutancous nacvi & - & - & - \\
\hline Varicose veins & - & - & - \\
\hline Early dental caries & $?$ & $?$ & + \\
\hline Normal IQ & + & + & + \\
\hline
\end{tabular}

facies, episodes of malignant hyperthermia, and anterior horn cell loss in one patient are compatible with either an underlying neuropathic process or a myopathic disorder of prenatal onset, even though muscle biopsies did not show specific changes of a known myopathy.

A maternal factor which would lead to the destruction of fetal muscle tissue in utero with retrograde loss of anterior horn cells is another aetiological consideration. Such a factor could be due to either a circulating antibody or a humoral factor. Alternatively, maternal stress such as fever could, in a fetus who had inherited a gene for malignant hyperthermia from the father, lead to an episode of intrauterine malignant hyperthermia with destruction of muscle tissue in utero. However, no evidence for malignant hyperthermia is present in either father, and no episode of fever during pregnancy was reported in the mothers.

With regard to the management of patients with this type of congenital contractures, it is important to point out that real time ultrasound investigations performed in mid-trimester in patient 2 of family 1 failed to diagnose an affected child before birth. This suggests that decreased intrauterine movement could not be distinguished early enough in pregnancy to make a diagnosis prenatally, even though the 
pattern of anomalies present at birth clearly speaks for a prenatal onset of the disorder. Nevertheless, we would strongly recommend prenatal real time ultrasound evaluations in any such family in the future, since ultrasound technology is continuing to improve all the time. Specific precautions before anaesthesia in patients with torticollis and congenital contractures in a pattern similar to these patients appears to be an appropriate recommendation to avoid precipitating unexpected episodes of malignant hyperthermia in patients who require surgery.

- In summary, the families presented here appear to represent a new form of arthrogryposis probably occurring as an autosomal recessive trait. The presence of torticollis in patients with congenital contractures should raise suspicion of this diagnosis. Because of the possibility of malignant hyperthermia, care should be taken during surgery or fever for any patients who have a similar phenotype.

U G Froster-Iskenius was supported by a grant from the Deutsche Forschungsgemeinschaft Fr 653/ 1-2. The March of Dimes has supported this work in part. The authors acknowledge the help of Drs Diane Lindner, Ute Ochs, Steve Chentow, Joel Haas, Susan Reed, David Shurtleff, and Patricia Hayden, and Ms Melanie Pepin.

\author{
References \\ 1 McDaniel A, Hirsch BE, Kornglut AD, Armbustuaches VM. \\ Torticollis in infancy and adolescence. Ear Nose Throat $J$ \\ 1984;63:478-87. \\ 2 Lidge RT, Bechtol RC, Lambert CN. Congenital muscular \\ torticollis. J Bone Joint Surg (Am) 1957:39:1165-82.
}

${ }^{3}$ Barenfeld PA, Weselcy MS. Congenital muscular torticollis: $\overrightarrow{\overline{\vec{S}}}$ case reports in siblings. Bull Hosp Joint Dis 1963;24:130-4. की

${ }^{4}$ Hummer CD, MacEwen GD. The coexistence of torticollis and $\bar{C}$ congenital dysplasia of the hip. J Bone Joint Surg $(A m)$ 1972;54:1255-6.

5 Isigbert E. Uuteosuchungen uber die Hereditat orthopadischev $\frac{\sigma}{\sigma}$ Leiden. III. De aujeborene Scichis. Arch Orthop Unfallchir $₫$ 1931;30:459-94.

- Clarren SK, Smith DW, Hanson JW. Helmet treatment for plagiocephaly and congenital muscular torticollis. J Pediatr $\vec{\circ}$ 1979:94:43-6.

7 Oh I, Nowacek CJ. Surgical release of congenital torticollis in $\vec{\omega}$ adults. Clin Orthop 1978;131:141-5.

${ }^{8}$ Hall JG, Reed SD, Rosenbaum KN, Gershanik J, Chen H, Wilson KM. Limb pterygium syndromes: a review and report of eleven patients. Am J Med Genet 1982:12:377-409.

${ }^{9}$ Relton YES. Malignant hypothermia - anaesthetic techniques o and agents. In: Britt BA, ed. International Symposium on N Malignant Hyperthermia. New York; Grune \& Stratton, 1973.

11) Denborough MA, Galloway GJ, Hopkinson KC. Malignant $\$$ hyperpyrexia and sudden infant death. Lancet 1982;ii:1068-9. 음

"Willner J. Malignant hyperthermia. Pediatr Ann 1984:13:12834.

12 Kelfer HM, Singer WD, Reynolds RN. Malignant hyperthermia $\underset{\mathbb{D}}{\mathcal{O}}$ in a child with Duchenne muscular dystrophy. Pediatrics 1983;71:118-9.

13 Brownell AKW, Paasuke RT, Elash A, et al. Malignant hyperthermia in Duchenne muscular dystrophy. Anesthesiology 1983;58:180-2.

${ }^{14}$ King JO, Denborough MA. Anesthetic-induced malignant $\infty$ hyperpyrexia in children. J Pediatr 1973;83:37-40.

15 McPherson EW, Taylor CA. The King syndrome: malignant hyperthermia, myopathy and multiple anomalies. Am J Med Genet 1981;8:159-65.

${ }^{16}$ Saul RA, Stevenson RE, Roberts TL. A female with the King syndrome in a family with elevated CPK levels. Proc Green- 응 wood Genet Center 1984;3:7-10.

Correspondence and requests for reprints to $\frac{\overline{\bar{O}}}{3}$ Professor Judith G Hall, Department of Medical Genetics, Clinical Genetics Unit, University of British Columbia, 4490 Oak Street, Vancouver, British Columbia, Canada V6H 3V5. 